\title{
Proton pump inhibitor indications in a Brazilian tertiary hospital
}

\author{
(D) Abadia Gilda Buso Matoso' \\ (D) Fernanda Arantes Mendonça Toledo Almeida² \\ (iD Lígia Paiva ${ }^{2}$ \\ (D) Patrícia Munhoz Margonari² \\ (iD Tainá Mendes Bertolin² \\ (iD)Alisson Alves Sousa ${ }^{2}$ \\ (iD) Ana Júlia Araújo de Carvalho ${ }^{2}$ \\ (iD) Ana Vera Cardoso Alves ${ }^{2}$ \\ (iD) Ébony Lima dos Santos ${ }^{2}$ \\ (iD Livia Lara Teodoro ${ }^{2}$ \\ (iD) Thiago Trajano da Silva²
}

\begin{abstract}
1. Mestre, médica especialista em Gastroenterologia, Departamento de Clínica Médica, Faculdade de Medicina, Universidade Federal de Uberlândia, Uberlândia, MG, Brasil

2. Discentes do curso de medicina da Faculdade de Medicina da Universidade Federal de Uberlândia, Uberlândia, MG, Brasil
\end{abstract}

http://dx.doi.org/10.1590/1806-9282.66.7.913

\section{SUMMARY}

OBJECTIVES: To evaluate the frequency of prescription of proton pump inhibitors (PPIs) and their indications in patients hospitalized at the Hospital de Clínicas of the Federal University of Uberlândia (HC-UFU).

METHODS: This is a quantitative cross-sectional observational study that analyzes data obtained from patient records on prescriptions of PPIs for patients hospitalized at the HC-UFU and from a questionnaire applied to assistant physicians on the indications of the drug in each case and evaluates the indication based on literature data.

RESULTS: On a pre-determined day, of a total of 462 inpatients, there was a prescription of PPI for 183 (39.3\%), with a higher frequency (73.5\%) in the Intensive Care Unit (ICU), followed by the infirmaries and the Emergency Room. The assistant physician was located in 116 cases, and the main motivation referred to prescription was prophylaxis of digestive hemorrhage (77\%). However, after reviewing medical records, it was noticed that in $50.8 \%$ of the cases, the prescription was not supported by the literature.

CONCLUSION: The frequency of PPI prescriptions for inpatients in the HC-UFU is among the lowest described in the literature, but there are still unnecessary prescriptions. Instruction and awareness of the assisting team can minimize these numbers.

KEYWORDS: Proton pump inhibitors. Gastrointestinal hemorrhage/prevention \& control. Therapeutic uses.

\section{INTRODUCTION}

Proton pump inhibitors (PPI) are potent blockers of acid secretion by the parietal cells of the stomach. They are widely used in the treatment of peptic diseases and in the prevention of gastrointestinal bleeding (GB) in high-risk patients ${ }^{1}$.

Among the indications for their prescription

DATE OF SUBMISSION: 12-Dec-2019

DATE OF ACCEPTANCE: 19-Jan-2020

CORRESPONDING AUTHOR: Lígia Paiva

Universidade Federal de Uberlândia (UFU), Faculdade de Medicina, Departamento de Clínica Médica

Av. Pará, 1720, Bloco 2H - Sala 1, Uberlândia, MG, Brasil - CEP 38400-902

Tel: +55 34 3225-8621

E-mail: ligiappaiva@gmail.com 
are the treatment and management of esophagitis, treatment of gastroesophageal reflux disease, reducing the risk of peptic ulcer associated with the use of non-steroidal anti-inflammatory drugs (NSAIDs), eradication of Helicobacter pylori infection in association with antibiotics, gastrinomas, treatment of gastric and duodenal ulcers, prophylaxis of lesion and GB in high-risk patients (respiratory failure, coagulopathy, etc.), as well as eosinophilic esophagitis, chemoprevention in Barrett's esophagus, and functional dyspepsia ${ }^{1}$.

The wide prevalence of gastrointestinal diseases associated with descriptions of the effectiveness of PPIs for the gastric protection of patients who use several drugs and the belief that the use of this class of medication presents a low risk of toxicity resulted in a significant increase in its prescription ${ }^{2}$. These factors, along with the low dissemination of guidelines on its correct use, have contributed to an increase in unnecessary indications of PPIs in admissions, particularly as a prophylactic drug ${ }^{2}$. Studies suggest that, in many cases, prescriptions are not based on scientific evidence $^{3}$; that improper use is still advised in some hospitalization protocols ${ }^{4}$, and most users take high doses in the long term unnecessarily ${ }^{5}$.

Although considered safe, PPIs have potential side effects, such as hypergastrinemia, deficient absorption of vitamin B12, iron, and magnesium, kidney failure, and gastric hyperplastic polyps. Its prolonged use is associated with a higher incidence of community-acquired pneumonia and diarrhea by Clostridium difficile ${ }^{1.6}$. Drug interactions can also occur, especially with clopidogrel and some anticonvulsant drugs. Unnecessary prescriptions also entail a significant expense in health care ${ }^{3}$. These conditions highlight the need for correct usage, according to specific guidelines ${ }^{1.2}$.

Hospital admission provides an opportunity for review of therapy, with the identification of current trends in prescription. Since there are no data representing the Brazilian reality, the present study seeks to identify the frequency of the use of PPIs in patients hospitalized in the Clinical Hospital of the Federal University of Uberlândia (HC-UFU), in addition to identifying the main indications for prescription and validating them, based on the literature. Our secondary objectives were to know the reasons for prescribing PPIs in these cases, identifying the routes of administration, and evaluating the adequacy of prescription in each case.

\section{METHODS}

This is a cross-sectional observational study with a quantitative approach that analyzed data on the prescription of PPIs obtained from medical records and a simple questionnaire applied to the assistant physician of patients hospitalized in the Hospital de Clínicas of the Federal University of Uberlândia (HC-UFU). The research was approved by the Research Ethics Committee of the Federal University of Uberlândia (CAAE 96762618.4.0000.5152; Opinion 2952760).

We used the descriptor "omeprazole" (only PPI available at HC-UFU) to select the medical records from the statistics department of the hospital. Initially, we surveyed the number of prescriptions of omeprazole per day, from January to March 2018. These numbers were used to calculate the average daily prescription of the drug. In a randomly chosen day of March 2018, we identified and selected for evaluation all records of patients who were in use of the medication at the hospital.

In addition, the total number of hospitalized patients in each sector (clinical and surgical infirmaries, emergency room, intensive care unit) on the chosen date was also considered to determine the frequency of the drug in the prescriptions of each sector of the HC-UFU.

After signing the Informed Consent Form, a questionnaire was applied to the assistant physician, containing questions about the indication of the use of omeprazole in each case.

We assessed patients' data such as age and gender, in addition to the identification of the hospital sector of hospitalization, route of administration, and use indication.

When GB prophylaxis was the justification given by physicians for prescribing a PPI, a review of the records was carried out in search of the criteria of such an indication. Based on the literature, the criteria are hospitalization in Intensive Care Unit (ICU) for more than seven days; mechanical ventilation for more than 48 hours; coagulopathy; a history of gastrointestinal bleeding in the past year; hidden gastrointestinal bleeding for six days or more; burns; sepsis, shock, or organic dysfunction; organ transplantation; head trauma; multiple trauma; Glasgow coma scale score less than 10; liver failure; spinal cord trauma; and use of corticosteroids in high doses ${ }^{7}$.

The analysis of the data was carried out based on descriptive statistics for the characterization 
of indicators (frequency, percentage, and average), comparing them with similar data available in the literature.

\section{RESULTS}

From January to March 2018, omeprazole was prescribed to an average of 205 patients per day (49.49\%). On the date determined for data collection, chosen at random from the month of March, there were 462 inpatients and 183 of them were using PPI, which corresponds to a prescription rate of $39.6 \%$.

The mean age of the patients who were prescribed PPI was 50 years and $61 \%$ were male. The route of administration was intravenous in $77 \%$ of cases. Regarding the sector of hospitalization, the frequency of PPI prescriptions was $73.5 \%, 37.7 \%$, and $31.8 \%$ in the ICU, infirmaries, and emergency services (ES), respectively. In surgical infirmaries, the prescription rate was $56.6 \%$, whereas in clinical infirmaries it was $29.1 \%$.

It was possible to reach the assistant physician and get an answer on the indication of the drug in 116 cases (88\%). GB prophylaxis in high-risk patients motivated the prescription of omeprazole in $77 \%$ of the cases, followed by functional dyspepsia (9\%), and other indications detailed in Graph 1.

After reviewing the medical records in search of the criteria used for prescribing omeprazole as GB prophylaxis, we found that in $50.8 \%$ of cases there was no justification for such indication. When this data was stratified by sector of hospitalization, the indication was inadequate in $7 \%, 52 \%, 64 \%$, and $76 \%$

GRAPH 1. INDICATION ON THE USE OF OMEPRAZOLE, DESCRIBED BY THE ASSISTANT PHYSICIAN, FOR PATIENTS HOSPITALIZED IN THE HC-UFU ON A DAY OF MARCH 2018 (MATOSO ET AL.)

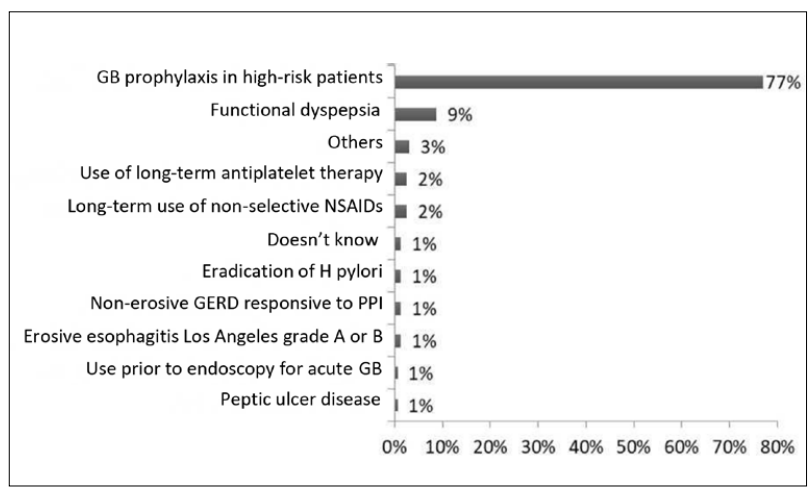

Legend: HC-UFU: Hospital de Clínicas of the Federal University of Uberlândia; GB: Gastrointestinal bleeding; NSAIDs: non-steroidal anti-inflammatory drugs; $\mathrm{H}$ pylor: Helicobacter pylori; GERD: Gastroesophageal reflux disease; PPI: Proton-pump inhibitor. Data obtained through the questionnaire applied to the assistant physicians at HC-UFU. of the prescriptions in the surgical infirmaries, clinical infirmaries, and ES, respectively, which can be observed in Graph 2.

\section{DISCUSSION}

Omeprazole was prescribed to $39.6 \%$ of patients hospitalized in the HC-UFU. When compared to similar studies conducted in tertiary hospitals, the frequency of PPI prescriptions identified in this study is low. In Ribeiro et al. ${ }^{8}$, the use of PPI in hospitalized patients of a Portuguese hospital was present in more than half of cases (54.2\%). Kelly et al. ${ }^{9}$ found PPI prescriptions in $57.5 \%$ of the cases of hospitalized patients in Ireland. In Spain, three similar studies presented PPI prescription frequencies the prescribed PPI well above the value found in the HC-UFU. Ameijeiras et al. ${ }^{10}$ identified a prevalence of $62.4 \%$ in the use of PPI at the university hospital of Santiago de Compostela. Ramirez et al. ${ }^{2}$ identified omeprazole prescriptions during hospitalization in $82.62 \%$ of patients in the University Hospital of Madrid. In another tertiary Spanish hospital, Villamañán et al. ${ }^{4}$ found a frequency of PPI prescription of $77.6 \%$ for inpatients.

Although the PPI prescription rate in the HC-UFU is among the lowest described in the literature, there was an inadequate prescription in almost half of the cases. GB prophylaxis was the main reason for the use of omeprazole (77\%), according to the assistant physicians. However, when reassessing the records in the search for criteria validated in the literature for such an indication, $50.8 \%$ of the cases presented no justification for the prescription. Similarly, Ribeiro et

GRAPH 2. ADEQUACY OF OMEPRAZOLE PRESCRIPTION FOR GB PROPHYLAXIS IN PATIENTS HOSPITALIZED IN THE HC-UFU (MATOSO ET AL.)

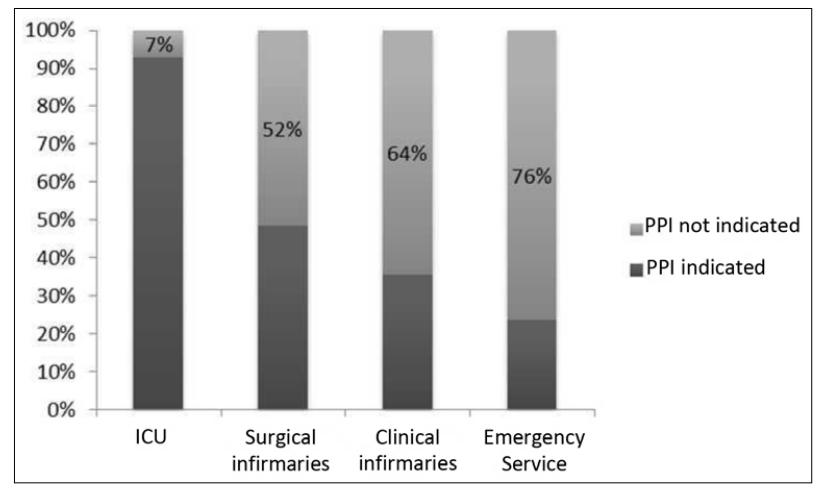

Legend: GB: gastrointestinal bleeding; HC-UFU: Hospital de Clínicas of the Federal University of Uberlândia; PPI: proton-pump inhibitor; ICU: Intensive Care Unit. Data obtained from the Medical Archive of HC-UFU. 
al. ${ }^{8}$ demonstrated an inappropriate use of PPI in $39.8 \%$ of all prescriptions for GB prophylaxis in non-critical patients. Ramirez et al. ${ }^{2}$ did not identify an appropriate indication in $61.25 \%$ of cases, especially for GB prophylaxis (17.34\%). Villamañán et al. ${ }^{4}$ also presented similar findings: unnecessary prescription of PPI in $63.6 \%$ of cases, with an inaccurate indication for GB prophylaxis in $19.8 \%$ of prescriptions. Another study identified the inappropriate use of PPIs at even higher rates. In Ameijeiras et al. ${ }^{10}$, the rate of incorrect prescriptions of PPI was $77.6 \%$, despite the existence of a specific protocol drawn up by the Committee of Pharmacy and therapeutics of this center.

Regarding the different sectors of hospitalization, the prescription rate of omeprazole was higher in the ICU (73.5\%) and in surgical infirmaries (56.6\%). The ICU, however, was the sector with the lowest rate of inappropriate prescriptions (7\%). The surgical infirmaries also had lower rates of inadequate prescription in comparison to the clinical infirmaries, i.e., $52 \%$ and $64 \%$, respectively.

Alsultan et al. ${ }^{11}$ found similar disparities in the inadequacy of intravenous PPI prescription for GB prophylaxis among patients hospitalized in the ICU (19.8\%) and in the other hospital sectors (71.7\%).

According to Heidelbaugh et al. ${ }^{12}$, because there are well-defined guidelines for the indication of PPIs in more severe patients, prescriptions in ICUs are usually more appropriate when compared to non-ICU sectors. However, the authors alert PPIs should be discontinued after the patients are transferred from the ICU, otherwise, there may be unnecessary continuous use in other sectors after the transfer or even after hospital discharge.

A study conducted at a tertiary hospital in the United States showed that of the 248 patients in use of antisecretory therapy in the ICU, 215 continued to receive the drug after transfer to another hospital sector. Of these, $86.7 \%$ had no appropriate indication for continuing using the drug ${ }^{13}$.

Zink et al. ${ }^{14}$ identified that 196 of the 324 patients analyzed were unnecessarily using PPIs and that $34 \%$ of these were discharged while still using this drug. Wohlt et al. ${ }^{15}$ got similar results from a study in a tertiary hospital of the University of Wisconsin. Of the total number of patients who were transferred from the ICU while using PPIs, there was no justification for continuing the therapy with gastric suppressors in 189 (60\%) of them, and 96 (50.7\%) of these patients were discharged with a prescription for the drug.
The excess of PPI prescriptions during hospitalizations and continued use of the drug after patient discharge result in increased health costs for the institution, patients themselves, and taxpayers in general $^{12}$. In the United Kingdom, the cost of PPI prescriptions was $£ 425$ million in 2006 , and its estimated cost worldwide was $£ 7$ billion ${ }^{9}$. Moreover, the cost with anti-secretory therapy is behind only that of statins, estimated at more than \$11 billion annually in the United States, and, according to a British estimate, unnecessary expenses were around £2 billion worldwide in 2008. The substantial expenditures in PPI motivated researchers to develop strategies that are cost-effective and based on scientific evidence for anti-secretory treatments, including stepdown and use on-demand, but few clinicians follow these recommendations ${ }^{12}$.

The frequency of intravenous PPI prescription was high when compared to studies carried out in other tertiary hospitals. In the work of Ameijeiras et al. ${ }^{10}$, the intravenous route was chosen in $36.2 \%$ of all prescriptions of omeprazole. In $17.7 \%$ of these prescriptions, no justification was found for the use of the drug. Ribeiro et al. ${ }^{8}$ assessed the intravenous use from adequate prescriptions of PPI, and in approximately $13 \%$ of these, there was no contraindication for the oral use of omeprazole. This work did not aim to evaluate the adequacy of the route of PPI administration. However, the high frequency of intravenous prescription is noteworthy. It is known that this formulation also increases costs for the service and the risks to the patient.

There are no well-established protocols at the HC-UFU for prescribing and using PPIs. However, the information system provides a list of criteria for prophylactic indications of omeprazole each time the drug is prescribed. This must have contributed to the frequency of prescription at acceptable levels. Even so, the prescription could have been avoided in almost half of the cases.

\section{CONCLUSIONS}

This study alerts to the need for a more careful assessment in the prescription of PPIs for hospitalized patients. We noticed that its use, in many cases, may be unnecessary, costly, and dangerous. The definition and wide dissemination of indications, contraindications, risks, and benefits of the drug aimed at the clinical staff of the institutions are necessary for more aware and less costly prescriptions. 


\section{Author's Contribution}

Abadia Gilda Buso Matoso participated in the leadership and counseling throughout the research, from the drafting and submission to the Research Ethics Committee of the organization until the submission for publication. Acted as a leader in the conceptualization, data curatorship, formal analysis, investigation, methodology, project management, supervision, validation, visualization, writing (original draft, revision, and editing).

Fernanda Arantes Mendonça Toledo Almeida, Lígia Paiva, Patrícia Munhoz Margonari and Tainá Mendes Bertolin participated as an equal, from the drafting and submission to the Research Ethics Committee of the organization until the submission for publication. Acted as an equal in the data curatorship, investigation, methodology, project management, validation, visualization, and writing (original draft, revision, and editing). Had a supportive role in the formal analysis, along with the rest of the team.

Alisson Alves Sousa, Ana Júlia Araújo de Carvalho, Ana Vera Cardoso Alves, Ébony Lima dos Santos, Lívia Lara Teodoro and Thiago Trajano da Silva contributed as an equal in the data curatorship, research, methodology, and the original draft, along with the rest of the team. Had a supportive role in the concept, formal analysis, project management, viewing, and writing (revision and editing).

\section{RESUMO}

OBJETIVOS: Avaliar a frequência da prescrição de inibidores da bomba de prótons (IBPs) e suas indicações em pacientes internados no Hospital de Clínicas da Universidade Federal de Uberlândia (HC-UFU).

MÉTODOS: Estudo observacional transversal quantitativo, análise de dados obtidos em prontuários sobre prescrições de IBPs para pacientes internados no HC-UFU, aplicação de questionário aos médicos assistentes sobre as indicações do medicamento em cada caso e avaliação dessas indicações com base em dados da literatura.

RESULTADOS: Em um dia predeterminado, de 462 pacientes internados, houve prescrição de IBP para 183 (39,3\%), com maior frequência (73,5\%) em Unidade de Terapia Intensiva (UTI), seguida das enfermarias e do pronto-socorro (PS). O médico assistente foi localizado em 116 casos, a principal motivação referida para prescrição foi a profilaxia de hemorragia digestiva (77\%). Entretanto, após revisão de prontuários, percebeu-se que em 50,8\% a prescrição não era respaldada por literatura.

CONCLUSÃO: A frequência de prescrição de IBP para pacientes internados no HC-UFU está entre as menores descritas na literatura, mas ainda há prescrições desnecessárias. Orientação e conscientização da equipe assistente podem minimizar esses números.

PALAVRAS-CHAVE: Inibidores da bomba de prótons. Hemorragia gastrointestinal/prevenção e controle. Usos terapêuticos.

\section{REFERENCES}

1. Yadlapati R, Kahrilas PJ. When is proton pump inhibitor use appropriate? BMC Med. 2017;15(1):36.

2. Ramirez E, Lei SH, Borobia AM, Piñana E, Fudio S, Muñoz R, et al. Overuse of PPIs in patients at admission, during treatment, and at discharge in a tertiary Spanish hospital. Curr Clin Pharmacol. 2010;5(4):288-97.

3. Chia CT, Lim WP, Vu CK. Inappropriate use of proton pump inhibitors in a local setting. Singapore Med J. 2014;55(7):363-6.

4. Villamañán E, Ruano M, Lara C, Suárez-de-Parga JM, Armada E, Álvarez-Sala R, et al. Reasons for initiation of proton pump inhibitor therapy for hospitalised patients and its impact on outpatient prescription in primary care. Rev Esp Enferm Dig. 2015;107(11):652-8.

5. Haroon M, Yasin F, Gardezi SK, Adeeb F, Walker F. Inappropriate use of proton pump inhibitors among medical inpatients: a questionnaire-based observational study. JRSM Short Rep. 2013;4(8):2042533313497183.

6. Reid M, Keniston A, Heller JC, Miller M, Medvedev S, Albert RK. Inappropriate prescribing of proton pump inhibitors in hospitalized patients. J Hosp Med. 2012;7(5):421-5.

7. Barletta JF, Bruno JJ, Buckley MS, Cook DJ. Stress ulcer prophylaxis. Crit Care Med. 2016;44(7):1395-405.

8. Ribeiro S, Bathy J, Trabulo D, Cremers MI, Oliveira AP, Pedroso ME. Uso inapropriado de inibidores da bomba de protões num serviço de medicina interna. J Port Gastroenterol. 2014;21(1):9-14.
9. Kelly OB, Dillane C, Patchett SE, Harewood GC, Murray FE. The inappropriate prescription of oral proton pump inhibitors in the hospital setting: a prospective cross-sectional study. Dig Dis Sci. 2015;60(8):2280-6.

10. Ameijeiras AH, González BC, Zúñiga VL. A survey of gastroprotective drugs: prescription-indication in hospitalized patients. Gac Sanit. 2007;21(5):412-5.

11. Alsultan MS, Mayet AY, Malhani AA, Alshaikh MK. Pattern of intravenous proton pump inhibitors use in ICU and non-ICU setting: a prospective observational study. Saudi J Gastroenterol. 2010;16(4):275-9.

12. Heidelbaugh JI, Kim AH, Chang R, Walker PC. Overutilization of proton-pump inhibitors: what the clinician needs to know. Therap Adv Gastroenterol. 2012;5(4):219-32.

13. Murphy CE, Stevens AM, Ferrentino N, Crookes BA, Hebert JC, Freiburg CB, et al. Frequency of inappropriate continuation of acid suppressive therapy after discharge in patients who began therapy in the surgical intensive care unit. Pharmacotherapy. 2008;28(8):968-76.

14. Zink DA, Pohlman M, Barnes M, Cannon ME. Long-term use of acid suppression started inappropriately during hospitalization. Aliment Pharmacol Ther. 2005;21(10):1203-9.

15. Wohlt PD, Hansen LA, Fish JT. Inappropriate continuation of stress ulcer prophylactic therapy after discharge. Ann Pharmacother. 2007;41(10):1611-6. 